\title{
PETRA CHRISTIAN UNIVERSITY STUDENT EXECUTIVE BOARD (BEM) PROJECT MANAGEMENT SYSTEM
}

\author{
Yulia $^{1}$, Arlinah Imam Rahardjo ${ }^{1}$, and Suryani ${ }^{2}$ \\ ${ }^{1,2}$ Informatics Department, Faculty of Industry Technology, Petra Christian University \\ Jl. Siwalankerto 121-131, Surabaya \\ Email: yulia@petra.ac.id
}

\begin{abstract}
Petra Christian University Student Executive Board (BEM) needs an administrative and project management system that can help managing the activities. This Board was having a problem of coordination on managing the activities they have. The tight schedule of each member of the executive staffs who comes from different departments has created this problem. To answer the above problem, an administrative and project management system is developed to help PCU BEM managing each of their activities. The scope of the system covers access privileges, job divisions and task assignments, proposal creation and budgeting arrangements of the implementation of each activity. The application is developed as a web-based system using Macromedia Dreamweaver MX 2004, PHP and JavaScript programming language and MySQL database system. The system testing concludes that the application is able to support the performances of the BEM executive staff members in managing their activities. The detailed job divisions let the implementation process of each activity be easily viewed by each executive staff member.
\end{abstract}

Keywords: Administrative system, Student Executive Board, Project Management.

\section{INTRODUCTION}

Petra Christian University (PCU) Student Executive Board (BEM) is an executive board responsible for managing the extra-curiculer activities of $\mathrm{PCU}$ students. It is in charge of channeling the PCU students' aspirations. PCU BEM consists of participating students from various departments at PCU. The activities of the Board consist of coordinating, planning and conducting long term and short term activities for students. One of the long term activities is related to extra-curicular Student Activity Unit (UKM) activities. UKM activities involve all PCU students who want to participate in the activities on their own interests. Meanwhile an example of short term activities, among them, is Petra Chess Competition conducted once a year (as stated on the policy of BEM).

In conducting a student activity, BEM needs an approval from Vice Rector III, the university administrator responsible for students activities. A request letter and an activity proposal have to be written and signed by the head of BEM to obtain the approval from Vice Rector III. After the implementation of each activity is completed, a report as a form of responsibility is also necessary to be submitted. The creating or request letters, proposals and reports of responsibility are used to be conducted manually by BEM. During the above processes, discussions among the executive staff members of BEM related to the preparation and implentation of activities conducted are needed. However, amongst their tight intra-curricularr class activities, each of the executive staff members of BEM has different schedules. This problem of different schedules creates a problem in setting the right time to meet and discuss the activities.

Meanwhile the emerging internet technology has the benefits of providing easy accesses to information resources from all over the world. The internet technology is also a promising solution for taking care on the problem of time limitation faced by PCU BEM. Thus BEM needs an application to manage the implementation of BEM activities smoothly as planned including involving people related to the implemented activities. The web-based application is expected to help the BEM executive staff members to implement, monitor and evaluate the activities anytime and from anywhere. This web-based application is also expected to help managing the administrative functions at BEM such as retrieving incoming and out-coming letters, proposals and reports archived in the system.

\section{RELATED WORKS}

Similar application has been developed as a project management software application for Vision and Mission Vision and Mission Educational Foundation (YPVM) [2]. YPVM is an educational foundation providing trainings and workshop programs as well as seminars for Christian teachers. This foundation was facing problems in integrating and monitoring all activities anytime and from anywhere to be able to produce useful information needed by 
the foundation to manage and develop further programs.

A project management system application is developed to aid the foundation in executing their programs in its best performance. This application covers access priveleges, jobs arrangement, budgeting arrangement of each activity. The data processing are integratedly arranged. This applicatrion is developed as a web-based application using the PHP and Javascript programming language and MySQL database system.

\section{BASIC CONCEPTS}

\section{Project}

Project management focuses on a project. Project is an effort having a start and end point and is conducted to reach the goal having been set up related to budgeting, scheduling and quality achievement objectives [1].

Each project is limited by scope, time and cost. These aspects are often used in project management as three main limitations [3]. To complete a project successfully, a project manager has to consider:

- Scope: what kind of tasks conducted as parts of the project? What products, services or results are desired by customers (sponsors) in a project?

- Time: how long will it take to complete a project?

- Cost: how much is the cost needed to complete a project?

\section{Project Management}

Project management united and optimized the required resources to complete a project successfully. The resources included competencies, talents and team work efforts, facilities, tools and equipments, information, system, techniques and money [1].

Project management concept as a discipline was developed to be used in managing US spacecraft programs at the beginning year of 1960 . This effort was further developed fast at government, military and industry.

Every project moves through a predictable lifecycle consisting of four phases in implementing the project. In managing each phase, various competencies are needed. Those phases of life-cycle of a project are:

- Setting up and defining the project

- Planning the project

- Implementation of the plan

- Completing and evaluating the project

\section{SYSTEM ANALYSIS}

PCU BEM's main activities are to implement long term activities such as UKM activities and short term activities for students. The activities cover processes such as letter creating, proposal and report creating. Those processes used to be conducted manually using Microsoft Word and Microsoft Excel. It took quite some times to retrieve those letters, proposals and reports as they were documented as hardcopies.

The proposals, prepared by the Board, are meant as the initial preparation at the planning stage of implementing activities for the students. The approved proposals will lead to other preparations to implement the activities, which will also be followed by an evaluation stage covering the report writing on activity as well as on budget realization as a form of responsibility.

PCU BEM has been progressing lately. It needs an administrative and project management system to aid the members in managing the information needed to plan, implement and evaluate the activities held. To develop a new system, an analysis of the current system is needed as a foundation to design a new system to meet the needs of PCU BEM.

\section{PROBLEM ANALYSIS}

PCU BEM has already have a website presenting information about BEM. However this website was not well managed nor functioning to its optimum. PCU BEM is in charge of managing and coordinating student activities. The old system used to manage the student activities was using a manual system. The administrative activities such as writing letters, developing proposals and reports writing were conducted using Microsoft Word and Microsoft Excel. The data created from those activities were kept separatedly by the secretary of each student activity. If a softcopy of a document was needed, the related secretary of the related activity had to be contacted. It took some times to find that person among thousands of students from different study programs. This old system created problems for the PCU BEM executive members to search for the documents created, especially those of the previous years, as the executive members are changing every year. It is hard to find the persons in charge if they graduate and can not be located. The old system also did not allow easy identifying and monitoring the progress of any activities anytime and from anywhere. 


\section{REQUIREMENT ANALYSIS}

PCU BEM needs a new website, not presenting the information about BEM only, but accommodating a system to handle the administration and project management of the student activities as well. The information about BEM can be accessed by public users, but the application for administration and project management can only be accessed by registered members of BEM or committee members of each activity. This new application is developed using the current development of information technology.

The new system for administrative works required by BEM provides easy data dan documents search such as letters, proposals and reports. The internet-based project management system covers the procedures from planning, writing letters and proposals, monitoring, evaluating and reports making. This internet-based monitoring system allows every member of BEM and committee of each activity to monitor and evaluate the progress of the activity anytime from anywhere. This new system is also expected to help the communication process among the executive members of BEM which are from different study program with his/her own school schedules.

\section{SYSTEM DESIGN}

Figure 1 and Figure 2 are the new developed system to process the activities. During the planning stage, a proposal creating activities is conducted electronically by the implementation committee member responsible for this task. The proposal is also checked against the initial plan and commented by the BEM executive staff members using the system.

The proposal will not be printed without any approval from BEM. The approved proposal is printed and submitted to the university administrator (University Vice President III) for approval before submitted to sponsors or related parties, such as speakers etc.

During the implementation stage, some processes such as defining task assignments for each member of the implementation committee are conducted electronically. In this stage, the progress of each task can be monitored anytime, anywhere.

During the evaluation stage, the report writing is also conducted and submitted electronically to BEM using this system. During the report creating stage, each task is evaluated and discussed electronically in details by the members of the implementation committee before being approved by BEM. The approved activity and budget realization report are submitted to the university administrator and sponsors in hardcopies.
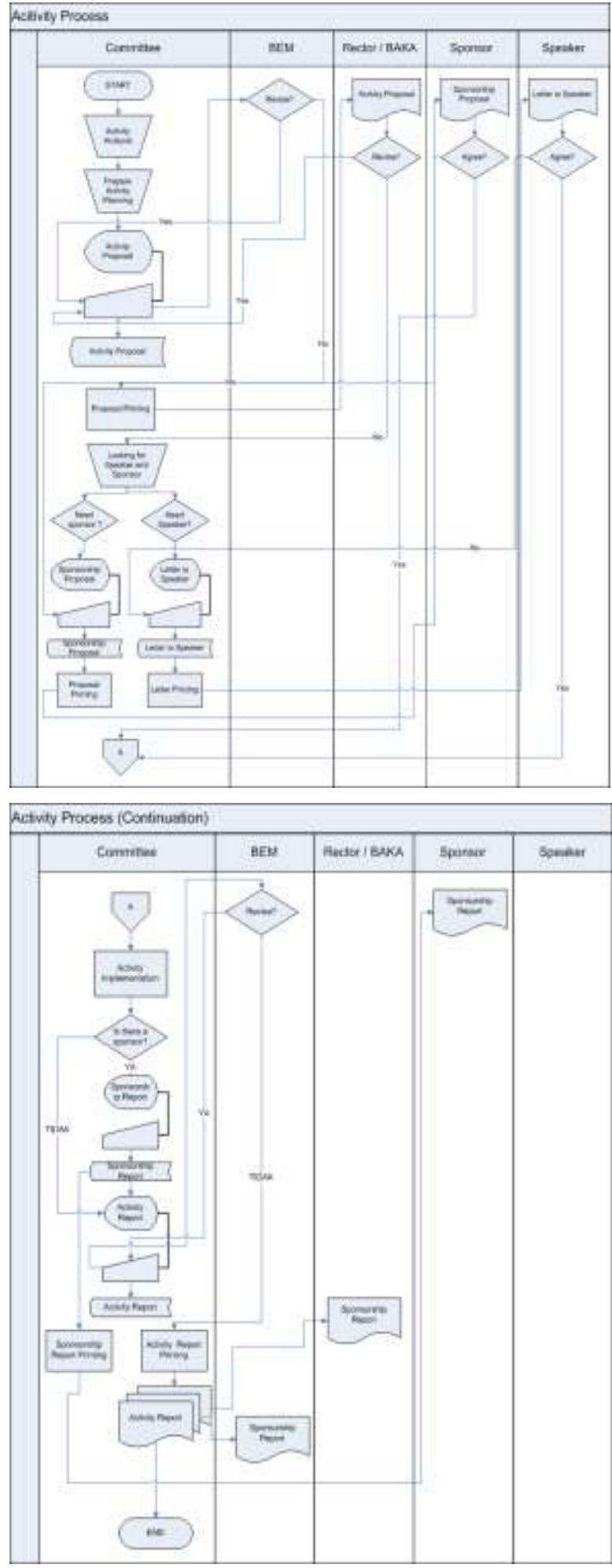

Figure 1. UKM Activity System/Other New BEM Activity

The new system is designed to manage the activities easier than the old system. This new system helps monitoring the progress of each activity conducted as well as in writing letters, proposals and reports in one web page. The data is also automatically stored in a database ready to be retrieved anytime needed. 
Figure 2 below is the design of Context Data Flow Diagram (DFD). The Context Diagram, depicts the overall system of administration and project management activities of BEM. The involved parties are committee members, Executive members of BEM, sponsors, resource persons, PCU administration staff, and BAKA.

The result of the DFD is developed into an ERDesign, presented at Figure 3 below.

\section{RESULT AND SYSTEM TESTING}

The system testing was conducted using a case study as follows. UKM on Voluntary Corp was going to implement an activity on Blood donor I, on May 5 2008. The preparation activities were started on April 152008 .
During the planning stage, a committee was formed by UKM on Voluntary Corp. The members of the committee were chosen from the members of the Voluntary Corp or non members. Thirteen students were chosen to be responsible for the implementation of this activity.

After the implementation committee was formed, each member involved started to prepare what were needed in implementing the activity. Each member was assigned tasks related to the position he/she had been appointed. Every task consists of three stages: planning (pre-implementation); realization (implementation), evaluation (post-implementation). Those tasks were determined on the committee meetings.

Based on the above case study, the steps needed were as follows:

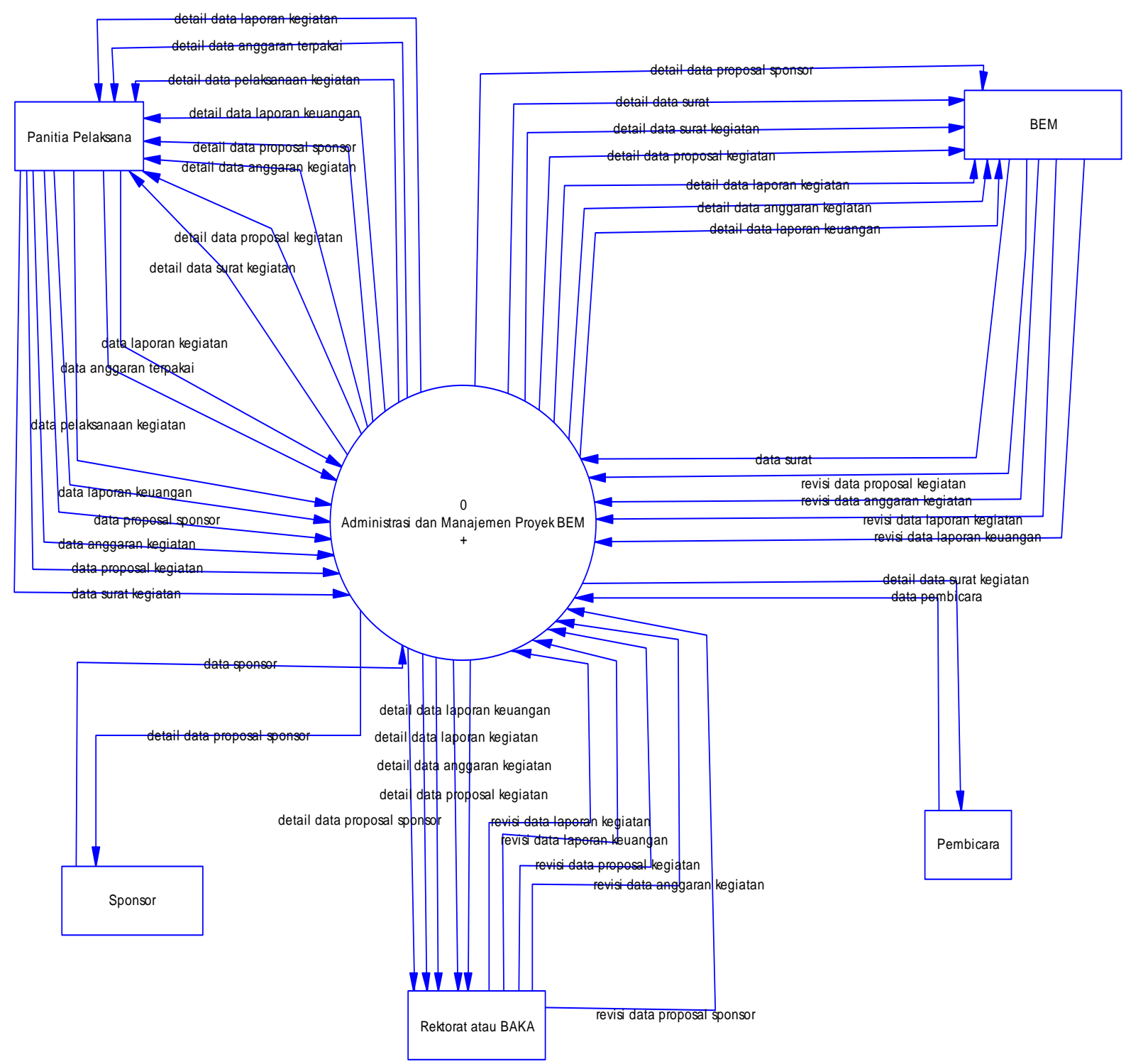

Figure 2. Context Diagram 


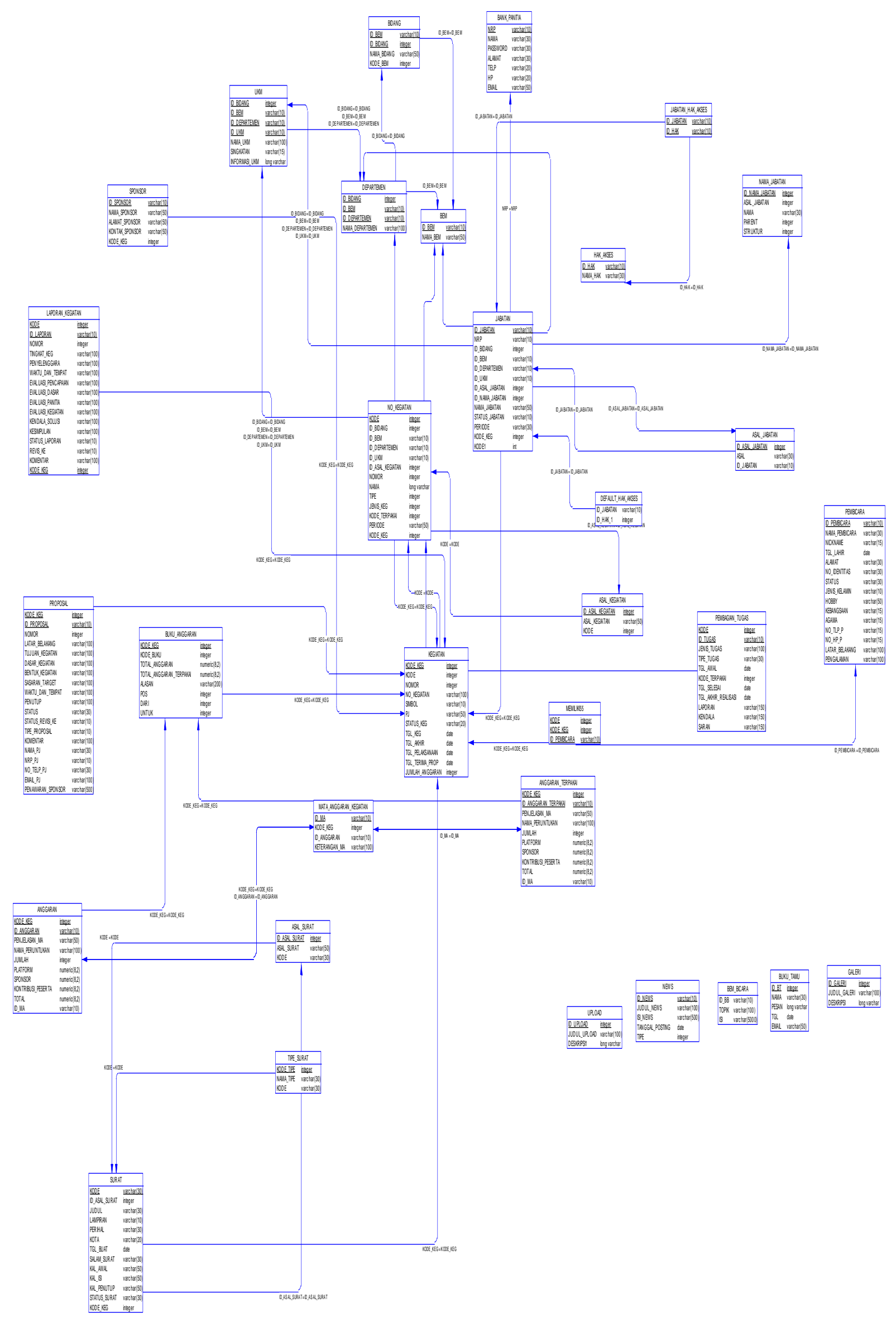

Figure 3. ER-Diagram 
1. A member of BEM executive staff did the data entry on the activities planned to be implemented.

2. A member of BEM executive staff did the data entry on the coordinator of the implementation committee

3. The coordinator of the implementation committee did the data entry of the members of the implementation committee

4. The secretary of the implementation committee did the data entry of the task assignments of each member of the implementation committee.

5. The proposal creating is conducted by the coordinator of the implementation committee

6. The letter creating is conducted by the secretary of the implementation committee

7. The budget plan is written by the treasurer of the implementation committee

8. Each member of the implementation committee wrote down the date as he/she completed the tasks. He/she also wrote the report related to his/her assignment.

9. The treasurer created the budget realization report from the data he/she provided

Figure 4 below showed the form for adding a new activity on Blood donors I. This activity was planned to be implemented on May $5^{\text {th }} 2009$, while the process was started on April $15^{\text {th }} 2009$. Thio Evi Yulia ( 42407201) was appointed as the person responsible for this activity.

After the new activity was formed, the secretary of BEM registered the coordinator of the activity. The coordinator formed an implementation committee as shown in Figure 5.

After the implementation committee was formed by the coordinator. The coordinator began to write a proposal for this activity by accessing the menu on creating Proposal. A proposal had to be created for each activity. Figure 6 showed the process of creating a proposal.

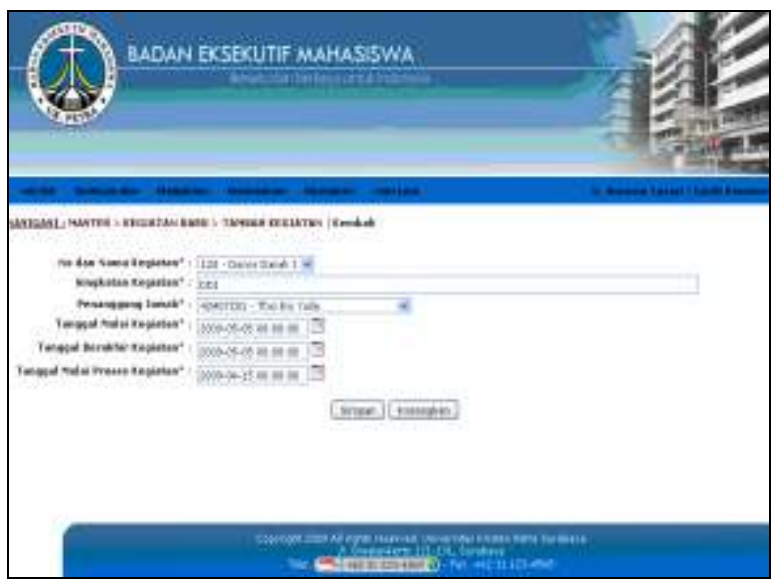

Figure 4. Inputting New Activity

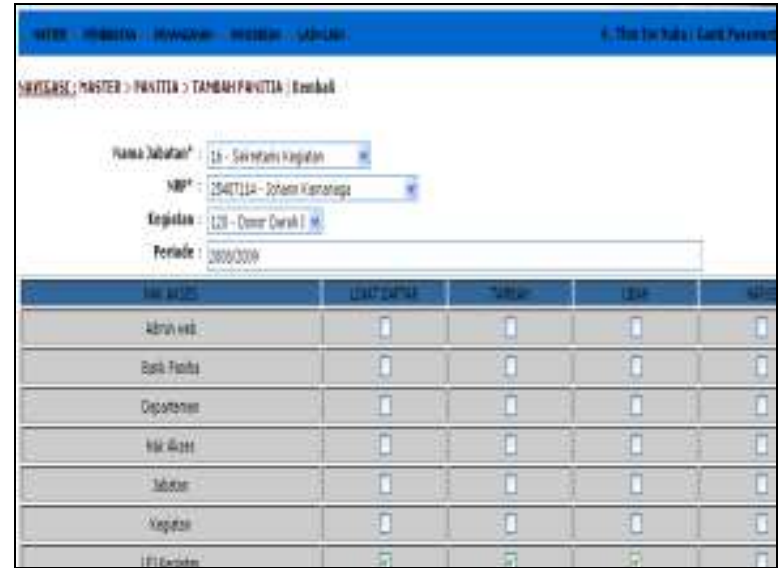

Figure 5. Inputting members of Implementation Committee

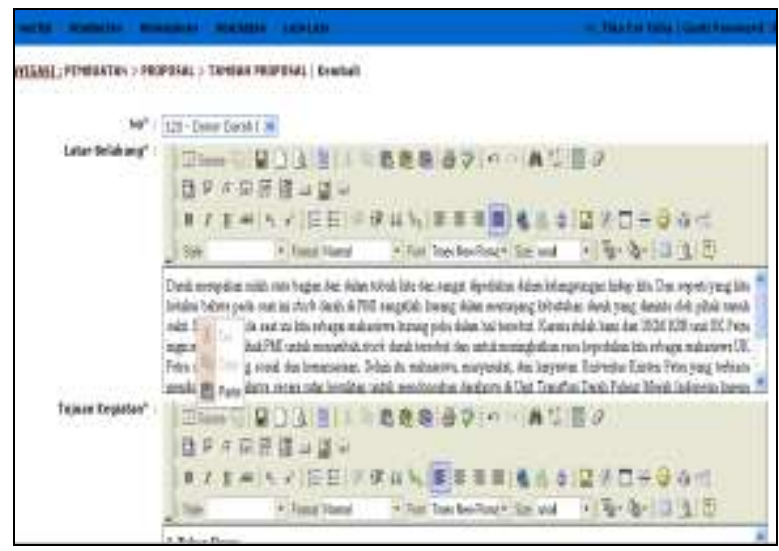

Figure 6. Inputting Proposal Page

The proposal was written directly using the template provided. The Proposal Menu could only be accessed by the coordinator and secretary of the implementation committee. The proposal consisted of background, objectives, and other things determined by BEM.

As the proposal was created, it could also be viewed by other persons under the positions for the activity on Blood Donor I., such as the Coordinator and Secretary of UKM on Voluntary Corp, The Head of the Department on Community Service up to the Head of BEM. Each proposal has a budget plan. The budget plan was created under the Budget menu and could only be accessed by the committee treasurer by login to the system using the access privilege assigned. The inputting process of the budget plan could be viewed on Figure 7.

The submitted proposal would be approved by the secretary of Voluntary Corps of UKM as seen on Figure 8. Spaces for comments were provided. Alter approval, the proposal would be submitted to the Voluntary Corps of UKM and The Head of BEM to be signed and approved, ready to be implemented. 


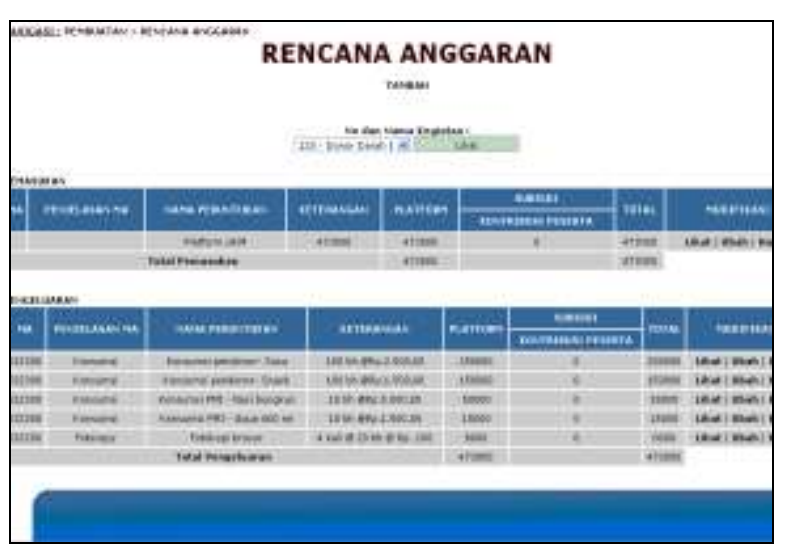

Figure 7.Budget Planning Page

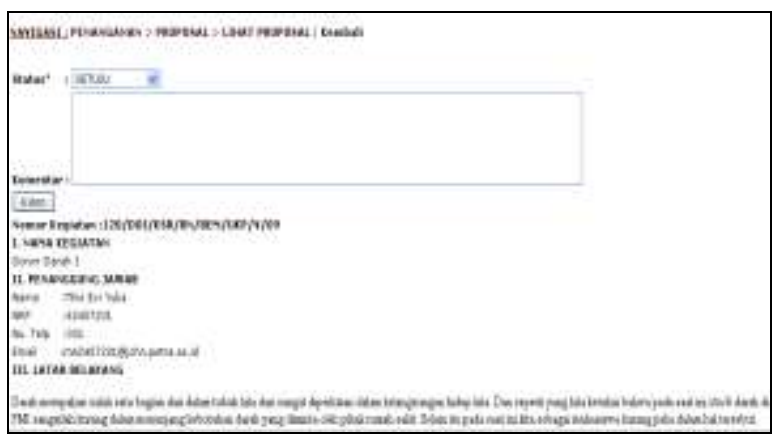

Figure 8. Proposal Writing Page

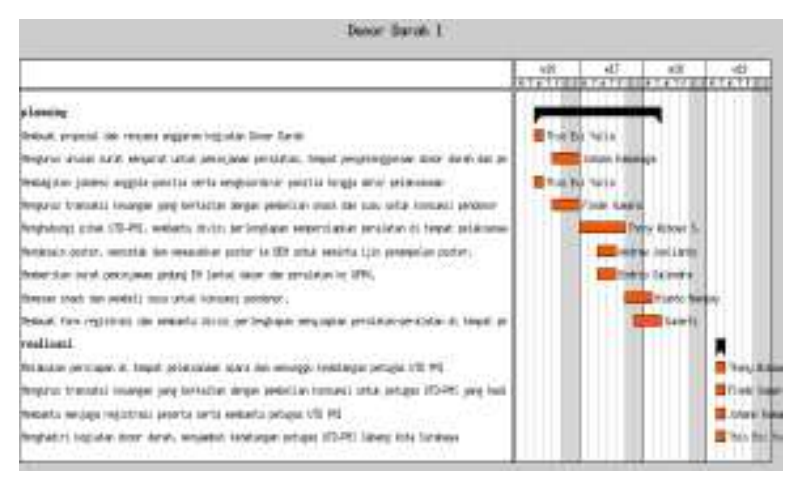

Figure 9. Gantt Chart - Job Division

Alter being approved by the Head of BEM; the Secretary of the implementation committee assigned the tasks assignments and schedules as seen on Figure 9.

Each member of the committee entered the performance progress having been achieved. Meanwhile the budget realization could only be written by the committee treasurer.

By the time of activities implementation has been completed, accountability report is required to made. The secretary of activity will make the report. Every accountability report will get checks like the making of activity proposal.
After the committee has carried out activities, then they have to make a financial report. During the evaluation stage, financial accountability report is prepared by the committee treasurer.

This application has been tested against 5 executive members BEM, as the users of the application, using questionnaires. The results can be viewed in Table 1. The ratings are 1 for the worst, up to 5 for the best. The results showed that most users gave 4 and 5 in term of interface, features, easy usage and conformity to the needs of BEM.

Table 1. Results of the Questionaires

\begin{tabular}{|c|c|c|c|c|c|c|}
\hline \multirow[t]{2}{*}{ No } & \multirow[t]{2}{*}{ Questions } & \multicolumn{5}{|c|}{$\begin{array}{l}\text { Numbers of } \\
\text { Respondent }\end{array}$} \\
\hline & & 1 & 2 & 3 & 4 & 5 \\
\hline 1 & $\begin{array}{l}\text { How interesting is the user } \\
\text { interface of the web-based } \\
\text { application designed for BEM } \\
\text { ? }\end{array}$ & 0 & 0 & 0 & 2 & 3 \\
\hline 2 & $\begin{array}{l}\text { Does the features of the web- } \\
\text { based application for BEM } \\
\text { support the performance of } \\
\text { BEM executive staff members } \\
\text { and implementation } \\
\text { committee }\end{array}$ & 0 & 0 & 1 & 2 & 3 \\
\hline 3 & $\begin{array}{l}\text { Is the web-based application } \\
\text { for BEM easy to use? }\end{array}$ & 0 & 0 & 1 & 3 & 1 \\
\hline 4 & $\begin{array}{l}\text { Does the web-based } \\
\text { application for BEM match } \\
\text { the current business process of } \\
\text { BEM? }\end{array}$ & 0 & 1 & 0 & 3 & 1 \\
\hline 5 & $\begin{array}{l}\text { Can the web application of } \\
\text { BEM be well implemented? }\end{array}$ & 0 & 0 & 0 & 4 & 1 \\
\hline
\end{tabular}

\section{CONCLUSION}

The administrative and project management system is expected to help BEM in creating letter requests, proposals and reports of responsibility more easily and better coordinated. This system allows each executive staff member of BEM and the implementation committee to have different access privileges. This feature helps BEM to better manage and document all activities as well as develop better senses of responsibility for each party involved.

Based on the results of the questionnaires, as described at Table 1, distributed to BEM executive staff members, it is concluded that the overall performance of application has been quite satisfactory as most of them gave 4 or 5 in their ratings to the questions.

\section{REFERENCES}

1. Haynes, Marion E. (1993) Manajemen proyek. Jakarta: Binarupa Aksara. 1993. 
2. Rahardjo, Arlinah I. (2010) Vision and Mission Educational Foundation (YPVM) Web-Based Project Management System. ICSIIT 2010.
3. Schwalbe, Kathy, (2006) PMP. Information technology project management. (4 ${ }^{\text {th }}$ Edition). Canada: Thomson Course Technology. 